\title{
Chromosomal Microarray Testing in 42 Korean Patients with Unexplained Developmental Delay, Intellectual Disability, Autism Spectrum Disorders, and Multiple Congenital Anomalies
}

\author{
Sun Ho Lee ${ }^{1 *}$, Wung Joo Song ${ }^{2}$ \\ ${ }^{1}$ Department of Diagnostic Laboratory Medicine, Chungnam National University Graduate School of Medicine, Daejeon 35015, Korea, \\ ${ }^{2}$ Department of Genetic Counseling, Konyang University Graduate School of Public Health and Welfare, Daejeon 35365, Korea
}

\begin{abstract}
Chromosomal microarray (CMA) is a high-resolution, high-throughput method of identifying submicroscopic genomic copy number variations (CNVs). CMA has been established as the first-line diagnostic test for individuals with developmental delay (DD), intellectual disability (ID), autism spectrum disorders (ASDs), and multiple congenital anomalies (MCAs). CMA analysis was performed in 42 Korean patients who had been diagnosed with unexplained DD, ID, ASDs, and MCAs. Clinically relevant CNVs were discovered in 28 patients. Variants of unknown significance were detected in 13 patients. The diagnostic yield was high $(66.7 \%)$. CMA is a superior diagnostic tool compared with conventional karyotyping and fluorescent in situ hybridization.
\end{abstract}

Keywords: autism spectrum disorder, chromosomal microarray, developmental delay, intellectual disability, multiple congenital anomalies

\section{Introduction}

Chromosomal microarray (CMA) analysis is widely recognized and recommended as the first-tier cytogenetic diagnostic test for patients with developmental delay (DD), intellectual disability (ID), autism spectrum disorders (ASDs), or multiple congenital anomalies (MCAs) [1, 2].

DD describes persons aged 5 years or younger who have demonstrated several significant delays in the following areas: cognitive, speech, social/personal, fine/gross motor, and daily activities. ID is diagnosed at or after age 5 years when one's intelligence quotient is deemed to be less than 70 and when permanent intellectual impairment results in a general deficit in adaptive behaviors [3]. ASD comprises a wide range of neurological and developmental disabilities, encompassing autism, Asperger syndrome, pervasive developmental disorders, and childhood disintegrative disorder [3]. MCAs refer to the presence of multiple major malfor- mations, such as cardiac defects and missing limbs, or 3 or more minor malformations (e.g., syndactyly and club feet).

Combined, these disorders are highly prevalent (DD/ID, up to $3 \%$ [4]; ASDs, $1 \%$ to $2 \%$ [5]; MCAs, $0.16 \%$ [6]) and might have a genetic etiology, such as copy number variation (CNV) and loss of heterozygosity (LOH). The prevalence of pathogenic CNVs is high in those with autism (5\% to $10 \%)$ and children with both ID and MCAs (20\% to 25\%) [7].

CMA is a high-resolution, high-throughput technique that detects submicroscopic CNVs that are not observable with traditional cytogenetic analysis tools, including karyotyping and fluorescence in situ hybridization (FISH) [8]. Further, CMA has a higher diagnostic yield $(12.2 \%$ on average) than conventional tests $[1,2]$. However, as with next-generation sequencing (NGS), interpreting microarray anomalies poses challenges for clinical laboratories and clinicians in establishing the clinical significance and pathogenicity of the detected CNVs.

Variability in the interpretation arises from internal 
databases that are limited by the number of cases that are analyzed; racial and socio-economic bias; and the complete lack of openly accessible centralized resources for sharing CMA data, patient phenotypes, and clinical interpretations between laboratories in South Korea and overseas. Moreover, disparate technology platforms with varying array designs, resolution, and coverage render the standardization of CMA and its uniform interpretation more difficult.

In this study, we attempted to establish the origin of DD, ID, ASDs, and MCAs in 42 Korean patients; demonstrate the value of CMA in determining the genomic etiology of unexplained DD, ID, and MCAs; and discuss the challenges facing CMA.

\section{Methods}

\section{Patients}

The parents and guardians of the probands were informed about the microarray study and given information about the risks, benefits, and limitations of CMA testing. Informed consent was obtained by a clinical geneticist or the researchers.

The study sample comprised 42 individuals ( 29 males, 13 females), ranging in age from newborns to 38 years, who had negative test results for metabolic disorders and other suspected disorders and did not present with any recognizable syndrome.

Clinical data, including medical history, were collected from the medical records and the parents and guardians of the probands. General observations for dysmorphic features were made, and the height and head circumference were measured by the clinician or the researchers.

\section{DNA preparation}

Blood samples were collected at the time of consent. Genomic DNA was extracted from peripheral blood lymphocytes using the AccuPure Cell/Blood DNA Mini Kit (AccuBioMed Co, Ltd, New Taipei City, Taiwan) according to the manufacturer's instructions. DNA concentration and quality were measured using a NanoDrop One Microvolume UV-Vis spectrophotometer (Thermo Fisher Scientific, Waltham, MA, USA) and a Fragment Analyzer (Advanced Analytical Technologies, Ankeny, IA, USA).

\section{Chromosomal microarray}

CMA tests were performed with Affymetrix CytoScan 750K arrays (Affymetrix, Santa Clara, CA, USA) and a GeneChip GCS3000dx V2 scanner (Affymetrix) according to the manufacturer's instructions. The array had 750,436 markers (550,000 non-polymorphic markers and 200,436 single nucleotide polymorphism markers), based on genome build hg19. The results were analyzed with Chromosome Analysis Suite ver. 3.2.0.1252 (Affymetrix).

\section{Interpretation}

CNVs were categorized as pathogenic, benign, and variants of uncertain significance (VUS) by considering gene content, size, inheritance pattern, and previously reported microdeletion or microduplication regions. University of California Santa Cruz Genome Browser was employed to check all of the information relevant to the locations of the CNVs. dbVar (https://www.ncbi.nlm.nih.gov/dbvar) and the Database of Chromosomal Imbalance and Phenotype in Humans using Ensembl Resources (https://decipher.sanger. ac.uk/) were consulted to check clinically relevant structural variations and determine whether the observed CNVs were of clinical significance. We considered CNVs to be causative if the variant was responsible for a known syndrome; encompassed a gene(s) of known function; or occurred de novo or, if inherited, the parent was variably affected or if the involved gene(s) had been reported to be associated with ID/DD/ASDs in public databases and the scientific literature. The term VUS was used if the variants affected a gene(s) of unknown clinical significance and if, at same time, the size was substantially less than $100 \mathrm{~kb}$ (the average resolution of the probes used) and when the family studies were inconclusive or unavailable [9].

\section{Results}

A total of 41 clinically relevant CNVs were detected in 28 (66.7\%) patients: three $(10.7 \%)$ of those presenting with MCAs, 23 (82.1\%) with a variable degree of DD or ID, and two (7.1\%) with varying degrees of ID and ASDs; 10 (35.7\%) patients had multiple rearrangements.

Among 28 pathogenic cases, nine were diagnosed with microdeletion/microduplication syndromes, including 1p36 deletion syndrome, 5q14.3 deletion syndrome, 16p11.2 deletion syndrome, 16p11.2 duplication syndrome, 19p duplication syndrome, 9p duplication syndrome, 19p13.2 deletion syndrome, and 22q11.2 duplication syndrome.

In this study, more pathogenic duplications were observed than deletions (22 vs. 19). Also, 12 cases (28.6\%) were VUS, and two cases $(4.8 \%)$ were benign CNVs (Table 1$)$.

\section{Discussion}

Genomic CNVs can contribute to the etiologies of DD, ID, ASDs, and MCAs. With its proven diagnostic yield, CMA has been recommended by a number of professional societies as part of the standard assessment for individuals in whom the underlying cause is unclear $[10,11]$. 
Table 1. Chromosomal microarray results

\begin{tabular}{|c|c|c|c|c|c|c|c|}
\hline $\begin{array}{l}\text { Patient } \\
\text { No. }\end{array}$ & Sex & Age & $\begin{array}{l}\text { Medical } \\
\text { history }\end{array}$ & Microarray result & $\begin{array}{l}\text { Size } \\
(\mathrm{kbp})\end{array}$ & $\begin{array}{l}\text { Critical gene(s) or } \\
\text { known syndrome }\end{array}$ & Classification \\
\hline \multirow[t]{2}{*}{1} & \multirow[t]{2}{*}{ M } & \multirow[t]{2}{*}{$7 y$} & \multirow[t]{2}{*}{ ID, ASD } & $\operatorname{arr}[$ hg19] 9q34.3(139,486,767-140,141,288)x3 & 654.521 & $\begin{array}{c}\text { THRB, GLB1, TRAF2, } \\
\text { MAN1B1, GRIN1 }\end{array}$ & \multirow[t]{2}{*}{ Pathogenic } \\
\hline & & & & arr[hg19] 3p24.2(24,448,650-24,453,383)x1 & 4.733 & $T H R B$ & \\
\hline \multirow[t]{2}{*}{2} & \multirow[t]{2}{*}{ M } & \multirow[t]{2}{*}{$2 y$} & \multirow[b]{2}{*}{$\begin{array}{l}\text { DD, dystonia, } \\
\text { family history } \\
\text { of hereditary } \\
\text { spastic } \\
\text { paraplegia }\end{array}$} & $\operatorname{arr}[$ hg19] 1q41q42.11(223,903,817-224,304,043)x3 & 400.226 & CAPN2 & \multirow[t]{2}{*}{ Pathogenic } \\
\hline & & & & arr[hg19] Xp21.1(32,535,197-32,544,026)x0 & 8.829 & $D M D$ & \\
\hline \multirow[t]{2}{*}{3} & \multirow[t]{2}{*}{ M } & \multirow[t]{2}{*}{$8 \mathrm{y}$} & \multirow[t]{2}{*}{ ID } & $\operatorname{arr}[$ hg19] $2 q 24.3(166,914,464-166,920,459) \times 1$ & 6 & SCN1A & \multirow[t]{2}{*}{ Pathogenic } \\
\hline & & & & $\operatorname{arr}[$ hg19] 3p26.3(282,750-283,756)x1 & 1 & CHL 1 & \\
\hline \multirow[t]{2}{*}{4} & \multirow[t]{2}{*}{ M } & \multirow[t]{2}{*}{9 y } & \multirow[t]{2}{*}{ ID } & $\operatorname{arr[hg19]~2q24.3(166,914,464-166,920,459)\times 1}$ & 6 & SCN1A & \multirow[t]{2}{*}{ Pathogenic } \\
\hline & & & & $\operatorname{arr[hg19]~Xp11.4(41,420,369-41,436,593)\times 0~}$ & 16 & CASK & \\
\hline 5 & M & $4 \mathrm{y}$ & DD & $\operatorname{arr}[$ hg19] Xq22.2(103,022,505-103,032,637)x0 & 10 & PLP1 & Pathogenic \\
\hline \multirow[t]{3}{*}{6} & \multirow[t]{3}{*}{ M } & \multirow[t]{3}{*}{9 y } & \multirow[t]{3}{*}{ ID } & $\operatorname{arr[hg19]~8q23.3(116,594,180-116,597,777)x1~}$ & 3.597 & TPRS1 & VUS \\
\hline & & & & arr[hg19] 19p13.3(1,377,665-1,712,859)x3 & 335.194 & NDUFST & \\
\hline & & & & $\operatorname{arr}[$ hg19] 20q13.33(61,914,225-62,223,211)x3 & 308.986 & KCNQ2 & \\
\hline 7 & M & 5 y & DD, dystonia & $\operatorname{arr}[$ hg19] $5 q 14.3 q 21.3(89,128,834-105,955,784) \times 1$ & $16,826.95$ & $\begin{array}{l}5 q 14.3 \text { deletion } \\
\text { syndrome }\end{array}$ & Pathogenic \\
\hline & & & & $\operatorname{arr}[$ hg19] Xp21.1(32,685,839-32,696,594)x0 & 10.755 & $D M D$ & \\
\hline 8 & M & $17 \mathrm{y}$ & Mild ID & $\operatorname{arr}[\mathrm{hg} 19]$ 2q21.2q21.3(134,274,063-135,144,454)x3 & 870.391 & None & Benign \\
\hline & & & & $\operatorname{arr}[$ hg19] 7q11.21(64,612,879-65,162,169)x1 & 549.29 & None & \\
\hline 9 & M & $7 y$ & ID, convulsion & $\operatorname{arr[hg19]~9q21.13q21.31~(74804031-81810541)x1~}$ & $7,006.51$ & TRPM6 & Pathogenic \\
\hline 10 & M & 16 y & $\mathrm{DD}, \mathrm{MCA}$ & arr[hg19] Xq28(152,927,530-153,002,877)x2 & 75.347 & SLC6AB & Pathogenic \\
\hline 11 & M & $17 \mathrm{y}$ & ID, ASD & arr[hg19]16p11.2(29,567,295-30,177,916x1 & 611 & $\begin{array}{l}\text { 16p11.2 deletion } \\
\text { syndrome }\end{array}$ & Pathogenic \\
\hline 12 & M & $10 \mathrm{mo}$ & $\begin{array}{l}\text { DD, hypotonia, } \\
\text { failure to thrive }\end{array}$ & arr[hg19]16p11.2(29,657,192-30,192,347)x3 & 598 & $\begin{array}{l}\text { 16p11.2 duplication } \\
\text { syndrome }\end{array}$ & Pathogenic \\
\hline 13 & M & NB & MCA & Normal (balanced de novo translocation later found) & - & N/A & Benign \\
\hline 14 & $\mathrm{~F}$ & 5 y & MCA & arr[hg19]1p36.33p36.23(849,466-7,637,060)x1 & 6,788 & $\begin{array}{l}\text { 1p36 deletion syn- } \\
\text { drome }\end{array}$ & Pathogenic \\
\hline 15 & M & 6 y & ID, ASD & $\operatorname{arr}[$ hg19] $2 q 14.2(121,565,880-121,569,723) \times 1$ & 3.843 & GLI2 & VUS \\
\hline 16 & $\mathrm{~F}$ & 5 y & DD, mitochon- & $\operatorname{arr}[$ hg19] $7 q 36.2(153,965,792-153,987,424) \times 1$ & 21.632 & DPP6 & Pathogenic \\
\hline & & & drial disorder & $\operatorname{arr}[$ hg19] $9 q 34.3(139,015,355-139,425,340) \times 3$ & 409.985 & NOTCH1 & \\
\hline & & & & arr[hg19] 12p13.33(1,953,989-2,306,966)x3 & 352.977 & CACNA2D4 & \\
\hline 17 & M & $7 \mathrm{y}$ & ID, multiple & $\operatorname{arr}[$ hg19] 9q34.3(139,870,881-140,169,934)x3 & 299.053 & MAN1B1 & Pathogenic \\
\hline & & & neuromuscular & $\operatorname{arr}[$ hg19] $16 p 13.3(549,826-1,045,161) \times 3$ & 495.335 & CCDC78 & \\
\hline & & & problems & $\operatorname{arr}[$ hg19] Xq28(153,167,262-153,189,112)x2 & 21.85 & AVPR2 & \\
\hline & & & & arr[hg19] Xp21.1(31,536,869-31,542,339)x0 & 5.47 & $D M D$ & \\
\hline 18 & $\mathrm{~F}$ & 15 y & $\begin{array}{l}\text { ID, seizure, } \\
\text { brain anomaly }\end{array}$ & arr[hg19] 16p11.2(32,046,521-33,814,547)x1 & $1,768.026$ & $\begin{array}{l}\text { 16p11.1 deletion } \\
\text { syndrome }\end{array}$ & Pathogenic \\
\hline 19 & $\mathrm{~F}$ & 15 y & ID & arr[hg19] Xp21.2(29,368,422-29,383,438)x4 & 15.016 & IL 1RAPL1 & Pathogenic \\
\hline 20 & M & 3 y & $\begin{array}{l}\text { DD, cryptorchi- } \\
\text { dism, dystonia }\end{array}$ & arr[hg19] $15 q 11.2(24,340,678-24,829,846) \times 3$ & 489.168 & PWRN1 & Pathogenic \\
\hline 21 & M & $6 y$ & $\begin{array}{l}\text { ID, dystonia, } \\
\text { long limbs }\end{array}$ & $\operatorname{arr}[$ hg19] $15 q 21.1 q 21.3(46,413,347-53,769,553) \times 1$ & 7356.206 & $F B N 1$ & Pathogenic \\
\hline 22 & M & 3 y & DD, dystonia & $\operatorname{arr}[$ hg19] 16p13.3(571,141-910,738)x3 & 339.597 & $C C D C 78$ & Pathogenic \\
\hline 23 & M & 14 y & DD, dystonia & $\operatorname{arr}[\mathrm{hg} 19]$ 16p13.3(1,002,394-1,007,394)x4 & 5.0 & LMF1 & Pathogenic \\
\hline & & & & arr[hg19] Xp21.1(31,536,869-31,536,878)x0 & 0.009 & $D M D$ & \\
\hline 24 & $\mathrm{~F}$ & 31 y & Mild ID & $\operatorname{arr[hg19]~15q26.3(99,183,519-99,204,934)\times 4~}$ & 21.415 & IGF1R & VUS \\
\hline 25 & M & 6 y & ID & 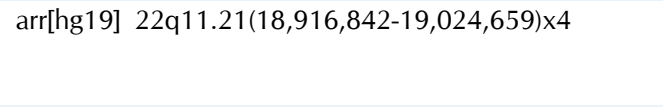 & 107.817 & $\begin{array}{l}\text { PRODH(22q11.2 } \\
\text { duplication synd- } \\
\text { rome) }\end{array}$ & Pathogenic \\
\hline 26 & $\mathrm{~F}$ & $27 \mathrm{y}$ & ID & arr[hg19] 9p24.3q21.11(208,454-69,977,404)x3 & $69,768.95$ & $\begin{array}{l}\text { 9p duplication syn- } \\
\text { drome }\end{array}$ & Pathogenic \\
\hline & & & & arr[hg19] 19p13.3(669,306-1,725,991)x3 & $1,056.685$ & $\begin{array}{l}\text { 19p duplication syn- } \\
\text { drome }\end{array}$ & \\
\hline
\end{tabular}


Table 1. Continued

\begin{tabular}{|c|c|c|c|c|c|c|c|}
\hline $\begin{array}{l}\text { Patient } \\
\text { No. }\end{array}$ & Sex & Age & $\begin{array}{l}\text { Medical } \\
\text { history }\end{array}$ & Microarray result & $\begin{array}{l}\text { Size } \\
(\mathrm{kbp})\end{array}$ & $\begin{array}{l}\text { Critical gene(s) or } \\
\text { known syndrome }\end{array}$ & Classification \\
\hline 27 & $\mathrm{~F}$ & $10 y$ & DD, epilepsy & $\operatorname{arr}[$ hg19] Xq28(152,765,599-153,008,454)×3 & 242.855 & $A T P 2 B 3, S L C 6 A B$ & Pathogenic \\
\hline 28 & M & 38 y & $\begin{array}{l}\text { History of DD, } \\
\text { hypotonia }\end{array}$ & arr[hg19] 7p21.2(16,438,181-16,443,839)x4 & 5.658 & $I S P D$ & VUS \\
\hline 29 & $\mathrm{~F}$ & $7 y$ & $\begin{array}{l}\text { History of DD, } \\
\text { polydactyly }\end{array}$ & $\begin{array}{l}\text { arr[hg19] } 7 q 35(146,193,991-146,199,530) \times 1 \\
\text { arr[hg19] Xp11.22(53,225,023-53,240,693)×3 }\end{array}$ & $\begin{array}{l}5.539 \\
15.67\end{array}$ & $\begin{array}{l}\text { CNTNAP2 } \\
\text { KDM5C }\end{array}$ & VUS \\
\hline 30 & M & $5 y$ & DD, dystonia & 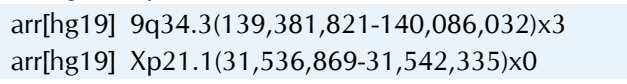 & $\begin{array}{r}704.211 \\
5.466\end{array}$ & $\begin{array}{l}\text { MAN1B1,GRIN1 } \\
D M D\end{array}$ & Pathogenic \\
\hline 31 & M & $18 \mathrm{y}$ & ID & $\operatorname{arr}[$ hg19] 9q34.3(139,897,180-140,086,032)x3 & 188.852 & MAN1B1,GRIN1 & Pathogenic \\
\hline 32 & $\mathrm{~F}$ & $11 \mathrm{y}$ & Mild ID, ASD & $\operatorname{arr}[$ hg19] 16p13.3(536,666-1,449,862)x3 & 913.196 & STUB1 & VUS \\
\hline 33 & M & $4 y$ & $\begin{array}{l}\text { DD, iron-defi- } \\
\text { ciency } \\
\text { anemia }\end{array}$ & $\begin{array}{l}\text { arr[hg19] } 7 p 15.2(27,223,591-27,224,687) \times 1 \\
\text { arr[hg19] } 16 p 13.3(1,129,251-1,517,728) \times 3\end{array}$ & $\begin{array}{r}1.096 \\
388.477\end{array}$ & $\begin{array}{l}\text { HOXA11 } \\
\text { GNPTG }\end{array}$ & VUS \\
\hline 34 & $\mathrm{~F}$ & $16 \mathrm{y}$ & $\begin{array}{l}\text { ID, low bone } \\
\text { density }\end{array}$ & $\operatorname{arr}[$ hg19] 1q21.3(151,331,913-151,409,973)x3 & 78.06 & POGZ & VUS \\
\hline 35 & M & $15 \mathrm{y}$ & $\begin{array}{l}\text { ID, low bone } \\
\text { density }\end{array}$ & $\operatorname{arr}[$ hg19] 1q21.3(151,331,913-151,409,973)x3 & 78.06 & POGZ & VUS \\
\hline 36 & $\mathrm{~F}$ & 5 y & $\begin{array}{l}\text { DD, hypotonia, } \\
\text { suspected } \\
\text { Haddad } \\
\text { syndrome }\end{array}$ & arr[hg19] 19p13.2p13.12(12,697,352-14,926,569)x1 & $2,229.217$ & $\begin{array}{l}\text { 19p13.2 deletion } \\
\text { syndrome }\end{array}$ & Pathogenic \\
\hline 37 & M & $13 y$ & ID & arr[hg19] Xp11.22(53,428,070-53,477,879)x2 & 49.809 & SMC1A & Pathogenic \\
\hline 38 & $\mathrm{~F}$ & $20 y$ & $\begin{array}{l}\text { History of DD, } \\
\text { convulsion }\end{array}$ & arr[hg19] Xp11.22(53,428,070-53,477,882)x3 & 49.812 & $S M C 1 A, H S D 17 B 10$ & Pathogenic \\
\hline 39 & M & $10 y$ & ID, ASD & $\begin{array}{l}\operatorname{arr}[\mathrm{hg} 19] 5 q 31.2 q 31.3(137,500,664-140,552,558) \\
\text { hmz }\end{array}$ & $3,051.894$ & $P U R A$ & VUS \\
\hline 40 & M & $6 y$ & ID & $\operatorname{arr}[$ hg19] Xq28(152,927,530-152,993,325)x2 & 65.795 & $A B C D 1$ & VUS \\
\hline 41 & M & $4 y$ & DD & $\operatorname{arr[hg19]} 1 \mathrm{p} 36.33(2,226,599-2,242,417) \times 4$ & 15.818 & SKI & Pathogenic \\
\hline 42 & $\mathrm{~F}$ & $21 \mathrm{y}$ & ID & $\operatorname{arr[hg19]~Xp22.32(5,844,864-5,872,572)\times 1~}$ & 27.70 & NLGN4X & VUS \\
\hline
\end{tabular}

ID, intellectual disability; ASD, autism spectrum disorders; DD, developmental delay; VUS, variantsof uncertain significance; MCA, multiple congenital anomalies.

Evaluating genomic variants identified by CMA is time-consuming and difficult. Variations in their interpretat ion are not uncommon due to platform differences (e.g., resolution and array design), lack of standardization, and differences in the resources that are available to and the expertise of the bioinformatics team and clinicians [12].

At the time of writing, South Korea's National Health Insurance (NHI) does not recognize CMA as a medically necessary test nor does it subsidize the cost of CMA testing. $\mathrm{NHI}$ allows only multiplex ligation-dependent probe amplification tests for four microdeletion syndromes: Angelman/Prader-Willi syndrome, DiGeorge syndrome, Miller-Dieker syndrome, and Williams syndrome [13]. Although subsidies for NGS genetic testing have received government approval this year, NGS tests are limited to a small number of pre-approved diagnostic gene panels. With NGS in the early stages of clinical application in this country due to government restrictions and due to insufficient human bioinformatics resources and lack of a central system for a nationwide interlaboratory QA program and data sharing, there is currently no affordable high-resolution, high-throu- ghput diagnostic genetic test for CNVs available to the public in South Korea.

One major limitation of this study is that due to the costs of CMA, we were unable to investigate the families of the probands to confirm the clinical significance of some detected CNVs. Other limitations were associated with the sensitivity and specificity of the chosen CMA testing platform; low-level mosaicism and balanced rearrangements might not be detected [14]. For example, in patient 26, FISH revealed a derivative chromosome 15 resulting from a translocation between chromosomes 9 and 15 .

This study illustrates the ability of CMA to greatly improve the diagnostic yield (66.7\%) for patients with unexplained DD, ID, ASDs, and MCAs. However, it is also important to note that the clinical impact of CMA beyond the diagnosis is very limited. It is unlikely that any genomic genetic test will lead to better clinical outcomes for adults with DD, ID, ASDs, and MCAs, because the genetic diagnosis often does not lead to an intervention strategy for adult patients. Nevertheless, the diagnosis will influence the parents' reproductive planning, assist genetic counselors in 
assessing recurrence risks and providing guidance to the patients' families, and ultimately help reduce childhood morbidity and mortality. Therefore, we recommend the introduction and recognition of CMA as the first-tier diagnostic genetic test in South Korea.

\section{Authors' contribution}

\author{
Conceptualization: SHL \\ Data curation: SHL, WJS \\ Formal analysis: SHL \\ Funding acquisition: SHL, WJS \\ Methodology: SHL \\ Writing - original draft: SHL \\ Writing - review \& editing: SHL, WJS
}

\section{References}

1. Miller DT, Adam MP, Aradhya S, Biesecker LG, Brothman AR, Carter NP, et al. Consensus statement: chromosomal microarray is a first-tier clinical diagnostic test for individuals with developmental disabilities or congenital anomalies. Am J Hum Genet 2010;86:749-764.

2. Bi W, Borgan C, Pursley AN, Hixson P, Shaw CA, Bacino CA, et al. Comparison of chromosome analysis and chromosomal microarray analysis: what is the value of chromosome analysis in today's genomic array era? Genet Med 2013;15:450-457.

3. American Psychiatric Association. Diagnostic and Statistical Manual of Mental Disorders: DSM-5. 5th ed. Washington, DC: American Psychiatric Association, 2013.

4. The National Academies of Sciences, Engineering, and Medicine. Mental Disorders and Disabilities Among Low-Income Children. Washington, DC: National Academies Press, 2015.

5. Centers for Disease Control and Prevention. Data \& statistics: Autism Spectrum Disorder (ASD). Atlanta: Centers for Disease Control and Prevention. Accessed 2017 Jul 7. Available from: https://www.cdc.gov/ncbddd/autism/data.html.

6. Calzolari E, Barisic I, Loane M, Morris J, Wellesley D, Dolk H, et al. Epidemiology of multiple congenital anomalies in Europe: a EUROCAT population-based registry study. Birth Defects Res A Clin Mol Teratol 2014;100:270-276.

7. Beaudet AL. The utility of chromosomal microarray analysis in developmental and behavioral pediatrics. Child Dev 2013;84:121-132.

8. Blue Cross Blue Shield Asssociation. Special report: chromosomal microarray for the genetic evaluation of patients with global developmental delay, intellectual disability, and autism spectrum disorder. Technol Eval Cent Assess Program Exec Summ 2015;30:1-4.

9. Richards S, Aziz N, Bale S, Bick D, Das S, Gastier-Foster J, et al. Standards and guidelines for the interpretation of sequence variants: a joint consensus recommendation of the American College of Medical Genetics and Genomics and the Association for Molecular Pathology. Genet Med 2015;17:405-424.

10. Michelson DJ, Shevell MI, Sherr EH, Moeschler JB, Gropman AL, Ashwal S. Evidence report: Genetic and metabolic testing on children with global developmental delay: report of the Quality Standards Subcommittee of the American Academy of Neurology and the Practice Committee of the Child Neurology Society. Neurology 2011;77:1629-1635.

11. Schaefer GB, Mendelsohn NJ; Professional Practice and Guidelines Committee. Clinical genetics evaluation in identifying the etiology of autism spectrum disorders: 2013 guideline revisions. Genet Med 2013;15:399-407.

12. Kaminsky EB, Kaul V, Paschall J, Church DM, Bunke B, Kunig $\mathrm{D}$, et al. An evidence-based approach to establish the functional and clinical significance of copy number variants in intellectual and developmental disabilities. Genet Med 2011;13: 777-784.

13. Shin S, Yu N, Choi JR, Jeong S, Lee KA. Routine chromosomal microarray analysis is necessary in Korean patients with unexplained developmental delay/mental retardation/autism spectrum disorder. Ann Lab Med 2015;35:510-518.

14. Rosenberg C, Knijnenburg J, Bakker E, Vianna-Morgante AM, Sloos W, Otto PA, et al. Array-CGH detection of micro rearrangements in mentally retarded individuals: clinical significance of imbalances present both in affected children and normal parents. J Med Genet 2006;43:180-186. 